\title{
Stability of Iron-Molybdate Catalysts for Selective Oxidation of Methanol to Formaldehyde: Influence of Preparation Method
}

Raun, Kristian Viegaard; Lundegaard, Lars Fahl; Beato, Pablo; Appel, Charlotte Clausen; Nielsen, Kenneth; Thorhauge, Max; Schumann, Max; Jensen, Anker Degn; Grunwaldt, Jan-Dierk; Høj, Martin

Published in:

Catalysis Letters

Link to article, DOI:

$10.1007 / \mathrm{s} 10562-019-03034-9$

Publication date:

2020

Document Version

Peer reviewed version

Link back to DTU Orbit

Citation (APA):

Raun, K. V., Lundegaard, L. F., Beato, P., Appel, C. C., Nielsen, K., Thorhauge, M., Schumann, M., Jensen, A. D., Grunwaldt, J-D., \& Høj, M. (2020). Stability of Iron-Molybdate Catalysts for Selective Oxidation of Methanol to Formaldehyde: Influence of Preparation Method. Catalysis Letters, 150, 1434-1444. https://doi.org/10.1007/s10562-019-03034-9

\section{General rights}

Copyright and moral rights for the publications made accessible in the public portal are retained by the authors and/or other copyright owners and it is a condition of accessing publications that users recognise and abide by the legal requirements associated with these rights.

- Users may download and print one copy of any publication from the public portal for the purpose of private study or research.

- You may not further distribute the material or use it for any profit-making activity or commercial gain

- You may freely distribute the URL identifying the publication in the public portal 


\title{
Stability of Iron-Molybdate Catalysts for Selective Oxidation of Methanol to
}

\section{Formaldehyde: Influence of preparation method}

\author{
Kristian Viegaard Raun ${ }^{1}$, Lars Fahl Lundegaard ${ }^{2}$, Pablo Beato ${ }^{2}$, Charlotte Clausen Appel ${ }^{2}$, Kenneth \\ Nielsen $^{3}$, Max Thorhauge $^{2}$, Max Schumann $^{1}$, Anker Degn Jensen ${ }^{1}$, Jan-Dierk Grunwaldt ${ }^{4}$, Martin Høj $^{1^{*}}$ \\ ${ }^{1}$ DTU Chemical Engineering, Technical University of Denmark, 2800 Kgs. Lyngby (Denmark) \\ ${ }^{2}$ Haldor Topsøe A/S, 2800 Kgs. Lyngby (Denmark) ${ }^{3}$ Department of Physics, Technical University of \\ Denmark, 2800 Kgs. Lyngby (Denmark) ${ }^{4}$ Institute for Chemical Technology and Polymer Chemistry, \\ Karlsruhe Institute of Technology (KIT), 76131 Karlsruhe (Germany) \\ *mh@kt.dtu.dk
}

\begin{abstract}
Iron molybdate/molybdenum oxide catalysts with varying content of $\mathrm{Mo}(\mathrm{Mo} / \mathrm{Fe}=1.6$ and 2.0$)$ were synthesized by a mild hydrothermal method and structurally characterized by XRD, XPS, Raman spectroscopy, SEM-EDS, BET and ICP-OES. The stability of the prepared catalysts in selective oxidation of methanol to formaldehyde was investigated by catalytic activity measurements for up to $100 \mathrm{~h}$ on stream in a laboratory fixed-bed reactor $\left(5 \% \mathrm{MeOH}, 10 \% \mathrm{O}_{2}\right.$ in $\mathrm{N}_{2}$, Temp. $\left.=380-407{ }^{\circ} \mathrm{C}\right)$. Excess $\mathrm{MoO}_{3}$ present in the catalyst volatilized under reaction conditions, which lead to an initial loss of activity. Interestingly, the structure of the excess $\mathrm{MoO}_{3}$ significantly affected the stability of the catalyst. By using low temperature hydrothermal synthesis, catalysts with the thermodynamically metastable hexagonal h- $\mathrm{MoO}_{3}$ phase was synthesized, which yielded relatively large crystals $(2-10 \mu \mathrm{m})$, with correspondingly low surface area to volume ratio. The rate of volatilization of $\mathrm{MoO}_{3}$ from these crystals was comparatively low, which stabilized the catalysts. It was furthermore shown that heat
\end{abstract}


treating a spent catalyst, subject to significant depletion of $\mathrm{MoO}_{3}$, reactivated the catalyst, likely due to migration of Mo from the bulk of the iron molybdate crystals to the surface region.

Keywords: Formox, Formaldehyde, iron molybdate, hexagonal MoO3, catalyst deactivation 


\section{Contents}

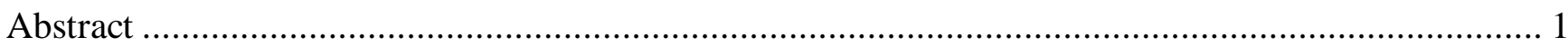

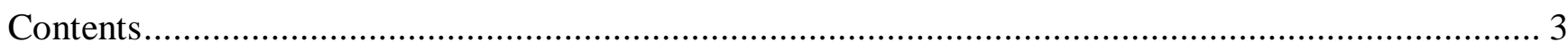

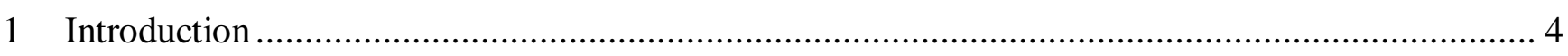

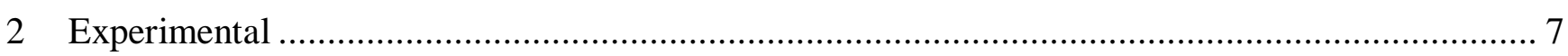

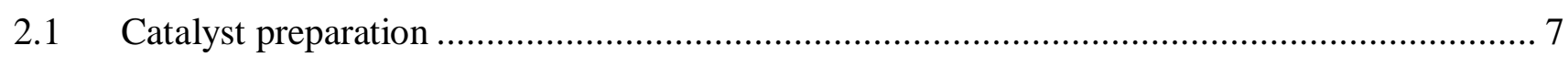

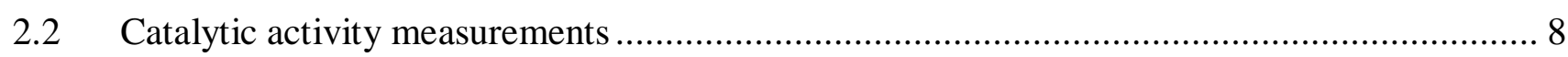

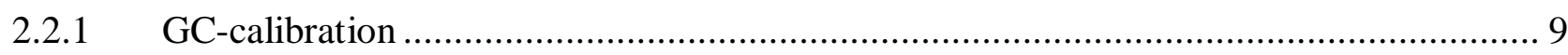

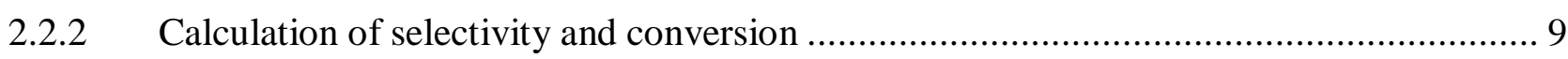

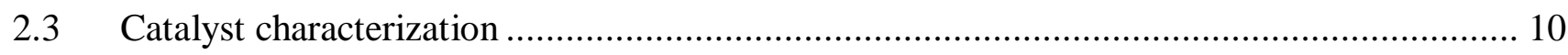

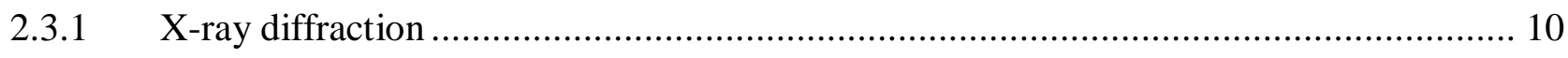

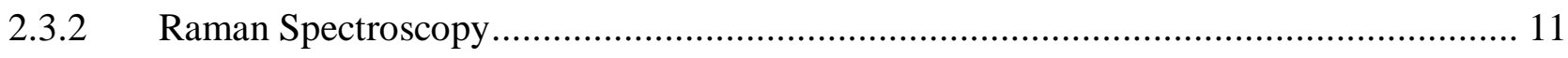

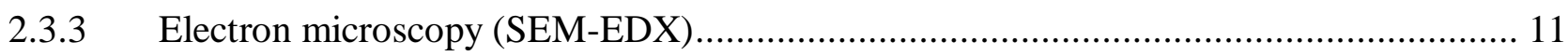

2.3.4 Surface analysis by X-ray photoelectron spectroscopy (XPS) ....................................... 11

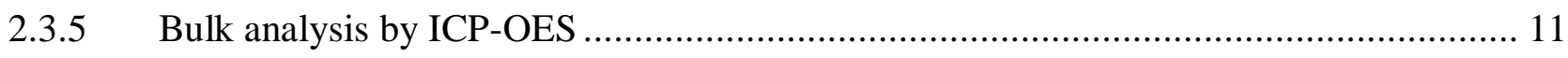

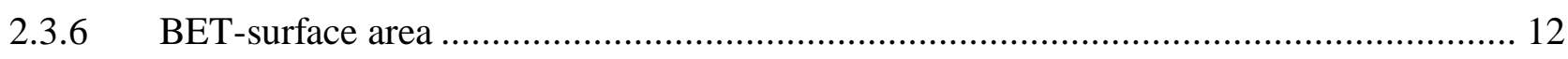

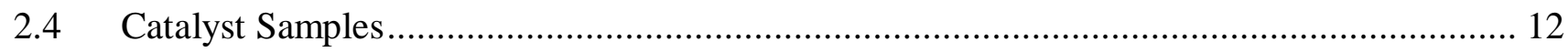

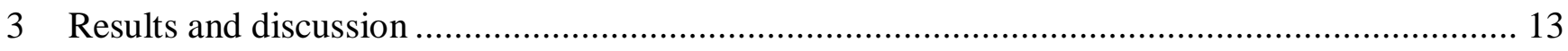

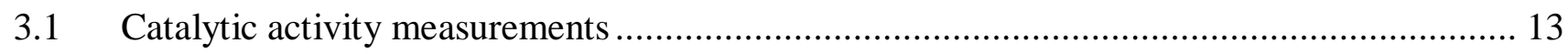

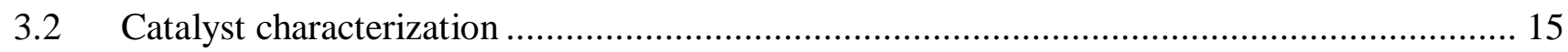

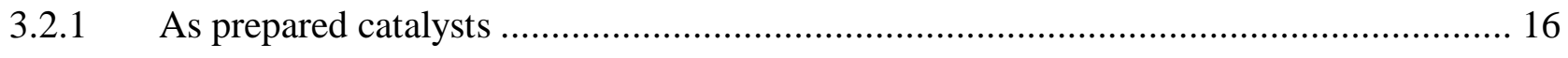

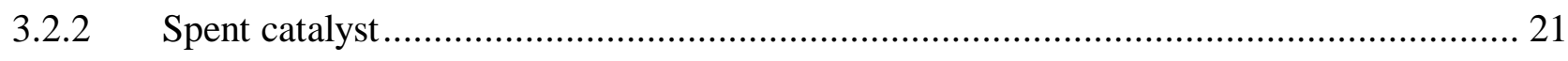

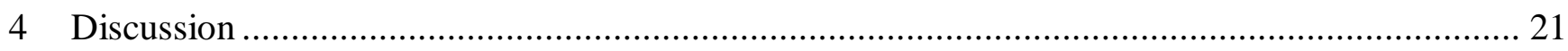

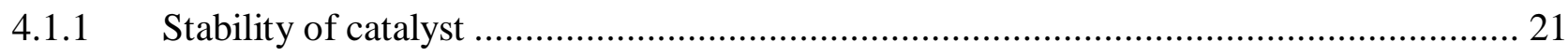

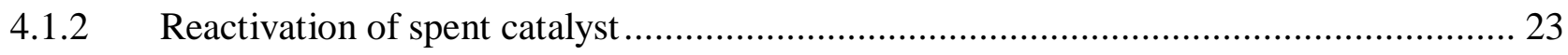

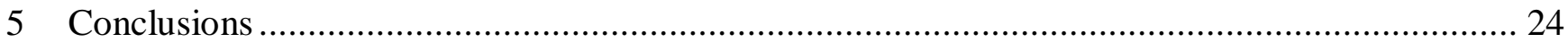

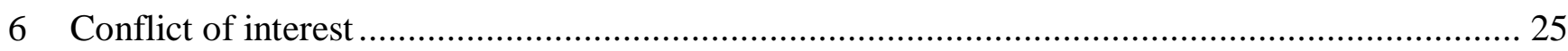

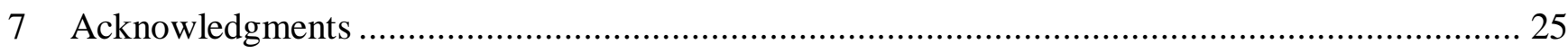

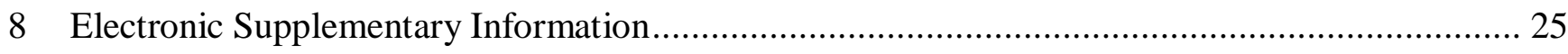

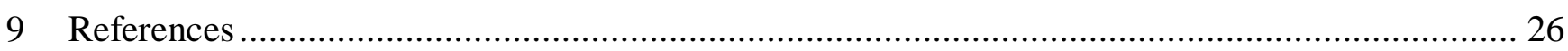




\section{Introduction}

Formaldehyde $\left(\mathrm{CH}_{2} \mathrm{O}\right)$ is one of the most important industrial intermediate chemicals, with a wide range of applications in chemical processes due to its high reactivity. In 2017 approximately 52 million tons of formalin ( $37 \mathrm{wt} . \%$ aqueous $\mathrm{CH}_{2} \mathrm{O}$ ) were produced, and with an estimated annual growth rate of over $5 \%$, the demand is increasing [1]. Formaldehyde is used industrially to produce a wide range of products, where formaldehyde resins account for approximately $75 \%$ of the consumption [2].

Formaldehyde is mainly produced from methanol by selective oxidation [3] according to reaction (1):

$$
\mathrm{CH}_{3} \mathrm{OH}+1 / 2 \mathrm{O}_{2} \rightarrow \mathrm{CH}_{2} \mathrm{O}+\mathrm{H}_{2} \mathrm{O} \Delta H=-156 \frac{\mathrm{kJ}}{\mathrm{mol}}
$$

The reaction is catalyzed by an iron molybdate/molybdenum oxide catalyst in a multi-tube fixed bed reactor with excess of oxygen $\left(\sim 10 \% \mathrm{MeOH}, \sim 5 \% \mathrm{H}_{2} \mathrm{O}, 10 \% \mathrm{O}_{2}\right.$ in $\left.\mathrm{N}_{2}\right)$ under slight over pressure ( 0.5 barg) [4]. The process is known as the Formox process [5]. The formaldehyde yield is between 88 to $92 \%$ with complete methanol conversion in a single pass. When the feed gas is introduced to the catalytic bed it is quickly heated due to the highly exothermic reaction (1), typically reaching 350 - 400 ${ }^{\circ} \mathrm{C}$ in the hot spot of the reactor [6]. The presence of water vapor, and relatively low concentration of oxygen in the feed gas is obtained by mixing recycle gas to the feed stream of methanol and air, which keeps the risk of explosion low [5]. The temperature should be kept below $400{ }^{\circ} \mathrm{C}$ to limit side reactions, such as formation of $\mathrm{CO} / \mathrm{CO}_{2}$ and to assure the stability of the catalyst [7].

Söderhjelm et al. [8] studied the synergy between the $\mathrm{MoO}_{3}$ and $\mathrm{Fe}_{2}\left(\mathrm{MoO}_{4}\right)_{3}$ phases in the iron molybdate catalyst. They tested catalysts with different Mo/Fe ratios $\left(\mathrm{Pure}_{\mathrm{Fe}} \mathrm{O}_{3}, 0.2,0.5,1,1.5,2.2\right.$ and pure $\mathrm{MoO}_{3}$ ). They achieved the highest selectivity and activity for the catalyst with a Mo/Fe ratio of 2.2. This catalyst consisted of a bulk phase of $\mathrm{Fe}_{2}\left(\mathrm{MoO}_{4}\right)_{3}$, bulk $\mathrm{MoO}_{3}$ and a surface layer phase of $\mathrm{MoO}_{x}$. They concluded that there is a synergy effect between the active surface layer $\left(\mathrm{MoO}_{x}\right)$ and the 
underlying sublayers $\left(\mathrm{Fe}_{2}\left(\mathrm{MoO}_{4}\right)_{3}\right)$ of the catalyst. The catalyst was as selective towards formaldehyde as pure $\mathrm{MoO}_{3}$, which is less active [9-11], and almost as active as pure $\mathrm{Fe}_{2}\left(\mathrm{MoO}_{4}\right)_{3}$, which is less selective. The synergy between the two phases in the iron molybdate catalyst thus yields a catalyst with both relatively high selectivity and activity. These observations have been confirmed by other researchers [12-14].

A major challenge for the Formox process is that molybdenum forms volatile species with methanol under reaction conditions, which leave behind an Mo depleted and less active catalyst [15-17]. Initially, the excess $\mathrm{MoO}_{3}$ volatilizes followed by volatilization of Mo from the ferric molybdate phase $\left(\mathrm{Fe}_{2}\left(\mathrm{MoO}_{4}\right)_{3}\right)$, present in the fresh catalyst, under formation of the reduced ferrous molybdate $\left(\mathrm{FeMoO}_{4}\right)$. Reduction of the ferric molybdate mainly takes place at temperatures above $300{ }^{\circ} \mathrm{C}[6]$. At substantial molybdenum loss, $\mathrm{Fe}_{2} \mathrm{O}_{3}$ can be formed. Due to segregation of molybdenum in ferric molybdate, this phase tends to have an over stoichiometric $\mathrm{Mo} / \mathrm{Fe}$ ratio on the surface [18]. Popov et al. [15] studied the deactivation and Mo volatilization from an iron molybdate/molybdenum oxide catalyst system $(\mathrm{Mo} / \mathrm{Fe}=1.5-2.5)$ under varying conditions of $\mathrm{MeOH}$ (up to 11.5 vol.\%) in air. They used a fixed bed reactor with a circulation loop and a trap for volatile Mo compounds placed downstream in the setup. They concluded that the rate of Mo volatilization is mainly affected by the methanol concentration and suggested the formation of the volatile compounds such as $\mathrm{MoO}_{2}\left(\mathrm{OCH}_{3}\right)_{2}$, $\mathrm{MoO}_{2}(\mathrm{OH})\left(\mathrm{OCH}_{3}\right), \mathrm{MoO}_{2}\left(\mathrm{OCH}_{3}\right)$ and $\mathrm{MoO}_{2}(\mathrm{OH})$. They observed that the volatile Mo species condensed as a blue film on the reactor tube inner surface at the reactor outlet and concluded that loss of Mo from the catalyst surface is the main reason for deactivation of the catalyst.

It is well known that volatile Mo compounds are transported through the industrial reactor and deposit downstream in the catalytic bed, which leads to an increased pressure drop [17]. The life time of the 
industrial process is only 1 to 2 years due to either loss of selectivity or development of a too high pressure drop, which is a major unsolved issue [16].

Commercial iron molybdate catalysts are usually prepared by co-precipitation followed by calcination [19], yielding an over-stoichiometric iron molybdate catalyst containing the $\mathrm{Fe}_{2}\left(\mathrm{MoO}_{4}\right)_{3}$ phase and the thermodynamically stable $\alpha-\mathrm{MoO}_{3}$ phase. However, $\mathrm{MoO}_{3}$ can form several crystal structures depending on preparation conditions. $\alpha-\mathrm{MoO}_{3}$ has an orthorhombic structure $\left(\beta=90^{\circ}\right)$ consisting of layers built from edge-sharing, distorted $\mathrm{MoO}_{6}$ octahedra and possesses terminal $\mathrm{Mo}=\mathrm{O}$ bonds [20]. Molybdenum trioxide can form two other metastable structures: $\beta-\mathrm{MoO}_{3}$, and hexagonal h- $\mathrm{MoO}_{3}$, which are typically synthesized at low temperature. $\beta-\mathrm{MoO}_{3}$ has a monoclinic structure, built by threedimensional corner-sharing octahedral $\mathrm{MoO}_{6}$ units. As oxygen atoms are multiply bonded to Mo atoms, only the surface positioned octahedral units possesses unshared corner oxygen atoms forming terminal $\mathrm{Mo}=\mathrm{O}$ bonds. $\beta-\mathrm{MoO}_{3}$ transforms to $\alpha-\mathrm{MoO}_{3}$ at around $450{ }^{\circ} \mathrm{C}[21]$. h- $\mathrm{MoO}{ }_{3}$ is a metastable hexagonal structure, that has been observed to transform to $\alpha-\mathrm{MoO}_{3}$ at 400 to $419{ }^{\circ} \mathrm{C}$ [22] [23]. We have studied the ageing of an iron molybdate/molybdenum oxide catalyst $(\mathrm{Mo} / \mathrm{Fe}=2)$ under reaction conditions $\left(25 \mathrm{mg}\right.$ catalyst, $5 \% \mathrm{MeOH}, 10 \% \mathrm{O}_{2}$ in $\mathrm{N}_{2}$, Temp. $=384-416{ }^{\circ} \mathrm{C}, \mathrm{W} / \mathrm{F}=1.2 \mathrm{~g}_{\text {cat }}$ $\mathrm{h} \mathrm{mol}^{-1} \mathrm{MeOH}$ ) for an extended period of up to $600 \mathrm{~h}$ [24]. Excess $\alpha-\mathrm{MoO}_{3}$ was shown to volatilize and leave the catalyst during the first $10 \mathrm{~h}$ on stream, leading to an initial decrease in activity of approximately $50 \%$. From 10 to $600 \mathrm{~h}$ on stream vaporization of molybdenum from the remaining iron molybdate phase $\left(\mathrm{Fe}_{2}\left(\mathrm{MoO}_{4}\right)_{3}, \mathrm{Mo} / \mathrm{Fe}=1.5\right)$ lead to formation of iron rich phases $\left(\mathrm{FeMoO}_{4}\right.$ and $\mathrm{Fe}_{2} \mathrm{O}_{3}$, $\mathrm{Mo} / \mathrm{Fe}<1.5)$ and simultaneously an increase in catalytic activity above the initial activity. Even at high degrees of molybdenum loss, the formaldehyde selectivity remained above $92 \%$, which was explained by a surface layer of $\mathrm{MoO}_{x}$ on the catalyst at all times due to segregation of Mo from the iron 
molybdate phase. After $600 \mathrm{~h}$ on stream, formation of $\beta-\mathrm{MoO}_{3}$ was observed, indicating that this molybdenum oxide phase is stable to some extent under reaction conditions. The initial loss of the $\alpha$ $\mathrm{MoO}_{3}$ was additionally confirmed and studied using operando X-ray diffraction (XRD), X-ray absorption spectroscopy (XAS) and Raman spectroscopy [25].

This work presents further studies of the iron molybdate catalyst system, its stability and ways to increase the stability. We have synthesized catalysts with varying Mo/Fe ratios (1.6 and 2.0) to show the effect of adding excess $\mathrm{MoO}_{3}$ to counter the effect of Mo volatilization. Furthermore, we show, for the first time, the stabilizing effect of synthesizing a catalyst $(\mathrm{Mo} / \mathrm{Fe}=2)$ with large crystals of h- $\mathrm{MoO}_{3}$ present as the excess $\mathrm{MoO}_{3}$ phase. The stabilizing effect may be utilized to extend the catalyst lifetime, which is only 1 to 2 years nowadays and the major technical issue in the industry. Finally, we show that Mo depleted catalysts can be reactivated by heat treatment.

\section{Experimental}

\subsection{Catalyst preparation}

The iron molybdate catalysts were prepared by hydrothermal synthesis similar to the procedure reported by Beale et al. [26] and previously used by the authors [24]. Iron nitrate nonahydrate $\left(\mathrm{Fe}\left(\mathrm{NO}_{3}\right) \bullet 9 \mathrm{H}_{2} \mathrm{O}-\right.$ Sigma Aldrich $>98 \%$ purity) and ammonium heptamolybdate tetrahydrate $\left(\left(\mathrm{NH}_{4}\right)_{4} \mathrm{Mo}_{7} \mathrm{O}_{24} \cdot 7 \mathrm{H}_{2} \mathrm{O}-\right.$ Sigma Aldrich $>99 \%$ purity) were dissolved separately in $150 \mathrm{~mL}$ of demineralized water each. The ammonium heptamolybdate solution was dropwise added to the iron nitrate solution under vigorous stirring. Some precipitation occurred immediately after mixing. The mixture was loaded in a $400 \mathrm{~mL}$ Teflon-lined autoclave (Berghof) with a magnetic stirrer and the $\mathrm{pH}$ was measured (1.7-2.2). The autoclave was sealed, heated to $180^{\circ} \mathrm{C}$ and kept at this temperature for 
hydrothermal treatment of the mixture for 12 hours. The solid product was filtered, washed with demineralized water and dried at $60{ }^{\circ} \mathrm{C}$ overnight yielding a yellow/green powder (yield $\approx 90 \%$ ).

\subsection{Catalytic activity measurements}

The synthesized catalyst powders were pressed into pellets, crushed and sieved to $150-250 \mu \mathrm{m}$ sieve fractions. A bed containing $25 \mathrm{mg}$ catalyst and $170 \mathrm{mg} \mathrm{SiC} \mathrm{(150-300} \mu \mathrm{m}$ sieve fraction) was placed between two plugs of quartz wool in a U-tube reactor (ID = $4 \mathrm{~mm})$. The reactor was placed in an oven. The feed gas consisted of $10 \mathrm{vol} \% \mathrm{O}_{2}$ and $\sim 5 \mathrm{vol} . \% \mathrm{MeOH}$ in $\mathrm{N}_{2}$, which was fed at a flowrate of $\sim 157.5 \mathrm{~mL} / \mathrm{min}(1 \mathrm{bar}, 273.15 \mathrm{~K}) . \mathrm{N}_{2}$ and $\mathrm{O}_{2}$ were introduced by mass flow controllers (Brooks) and bubbled through a flask containing $\mathrm{MeOH}(\geq 99.9 \%$, Sigma-Aldrich). The gas was saturated with $\mathrm{MeOH}$ and the concentration was controlled by cooling the bubble-flask in a cooling bath to $5^{\circ} \mathrm{C}$. To determine the conversion and selectivity the gas composition was measured at the outlet of the reactor by a gas chromatograph (GC) (Thermo Scientific, Trace GC Ultra). The MeOH and DME concentrations were measured using an FID-detector and the $\mathrm{CH}_{2} \mathrm{O}, \mathrm{H} 2 \mathrm{O}, \mathrm{CO}, \mathrm{CO}_{2}, \mathrm{O}_{2}$ and $\mathrm{N}_{2}$ concentrations were measured using a TCD-detector. The measured concentrations were corrected for expansion of the gas due to reaction using the $\mathrm{N}_{2}$ signal as internal standard [27]. Furthermore, the reactor inlet and outlet pressures were measured, and a thermocouple was placed inside the reactor touching the exit of the catalyst bed to measure the bed temperature. Before each experiment, the catalyst bed was thermally treated at $400{ }^{\circ} \mathrm{C}$ in air for two hours and the conversion was subsequently measured at increasing temperatures (oven temp. $=250,300,340$ and $375^{\circ} \mathrm{C}$ ) under reaction conditions to obtain the first order reaction rate constant as a function of temperature. Due to fast changes in the catalytic activity under reaction conditions, the oven temperature was increased without $\mathrm{MeOH}$ in the feed $\left(10 \% \mathrm{O}_{2}\right.$ in $\left.\mathrm{N}_{2}\right)$. When the oven temperature stabilized at the new set point, $\mathrm{MeOH}$ 
was introduced for $5 \mathrm{~min}$ followed by a gas composition measurement. The measurement at $375^{\circ} \mathrm{C}$ was also the first measurement of the following prolonged measurement of catalyst deactivation. The changes in the catalytic activity prior to the deactivation experiment were small due to the short exposure time and moderate temperature. The deactivation experiments ran for $100 \mathrm{~h}$ (oven temp. = $375^{\circ} \mathrm{C}, 1 \mathrm{GC}$-measurement per hour). After the $100 \mathrm{~h}$ test, the catalyst was heat treated at an oven temperature of $400{ }^{\circ} \mathrm{C}$ for $2 \mathrm{~h}$ under $10 \% \mathrm{O}_{2}$ and $90 \% \mathrm{~N}_{2}$, followed by a four hour run under the previous reaction conditions. This procedure was repeated with heat treatment at $500{ }^{\circ} \mathrm{C}$ for $2 \mathrm{~h}$. Finally, the catalyst was cooled to room temperature in the reaction gas mixture to maintain the catalyst state.

\subsubsection{GC-calibration}

Both GC detectors (FID and TCD) were calibrated using gas mixtures with known concentrations, except for formaldehyde due to its ability to polymerize at room temperature. The TCD detector was calibrated for formaldehyde using Lennard-Jones parameters to calculate the viscosity and thermal conductivity for formaldehyde and reference species $\left(\mathrm{N}_{2}, \mathrm{O}_{2}, \mathrm{MeOH}\right.$ and $\left.\mathrm{CH}_{4}\right)$. A linear trend between the TCD detector response factor and the thermal conductivity for the respective reference species were seen. The response factor of formaldehyde could be estimated by assuming a linear trend of the reference species [28-30]. The response factor of formaldehyde was similar to the response factors for $\mathrm{N}_{2}, \mathrm{O}_{2}$ and $\mathrm{MeOH}$, which have similar molar masses.

\subsubsection{Calculation of selectivity and conversion}

The conversion of methanol (X) and selectivity to formaldehyde (S) was calculated according to Equations (2) and (3): 


$$
\begin{gathered}
X=\left(1-\frac{P_{\mathrm{MeOH}}}{P_{\mathrm{MeOH}}+P_{\mathrm{CH}_{2} \mathrm{O}}+2 P_{\mathrm{DME}}+P_{\mathrm{CO}}+P_{\mathrm{CO}_{2}}}\right) * 100 \% \\
S=\frac{P_{\mathrm{CH}_{2} \mathrm{O}}}{P_{\mathrm{MeOH}}+P_{\mathrm{CH}_{2} \mathrm{O}}+2 P_{\mathrm{DME}}+P_{\mathrm{CO}}+P_{\mathrm{CO}_{2}}} * 100 \%
\end{gathered}
$$

The carbon balance with respect to all measured compounds closed within $7 \%$ (see ESI Figures S1 to $\mathrm{S} 4 \dagger)$.

Beside oxidation of formaldehyde into $\mathrm{CO}$ and $\mathrm{CO}_{2}, \mathrm{DME}$ is industrially observed as a side product. The formation of DME is a reversible reaction between two methanol molecules according to (4). At higher conversion levels DME will mainly be converted to formaldehyde yielding high overall selectivity.

$$
2 \mathrm{CH}_{3} \mathrm{OH} \rightleftarrows\left(\mathrm{CH}_{3}\right)_{2} \mathrm{O}+\mathrm{H}_{2} \mathrm{O}
$$

\subsection{Catalyst characterization}

\subsubsection{X-ray diffraction}

XRD data were collected using a PanAlytical Empyrean diffractometer equipped with focusing mirrors for $\mathrm{Cu} \mathrm{K}_{\alpha}$ radiation $(\lambda=1.541 \AA)$ and a capillary spinner. A Ni beta filter, a pair of 0.04 radian soller slits and a beam stop were used. Samples were measured in sealed capillaries. Rietveld refinement was performed using the TOPAS software [31] with reference structures for $\mathrm{Fe}_{2}\left(\mathrm{MoO}_{4}\right)_{3}$ [ICSD 80449], $\mathrm{FeMoO}_{4}$ [ICSD 43013], $\alpha-\mathrm{MoO}_{3}$ [ICSD 152313], h- $\mathrm{MoO}_{3}$ [ICSD 80291] and $\mathrm{Fe}_{2} \mathrm{O}_{3}$ [ICSD 15840]. Atomic positions and stoichiometry were fixed, while lattice parameters, average crystallite size and scale factors were refined. 


\subsubsection{Raman Spectroscopy}

Raman spectra were recorded with a Horiba LabRAM microscope, using $633 \mathrm{~nm}$ excitation. The samples were sealed in glass capillaries in order to avoid re-oxidation in air during measurements. A 50x long distance objective (Olympus) was used to focus the laser beam, with a measured power of 1 $\mathrm{mW}$ on the sample. Reference spectra for all relevant phases are shown in the Electronic Supplementary Information (ESI) Figure S5†.

\subsubsection{Electron microscopy (SEM-EDX)}

The particles were dispersed on double sided carbon tape on an aluminum stub and the samples were coated with an electron conductive layer of carbon prior to investigation. Scanning Electron Microscopy (SEM) images were acquired in an Environmental SEM, XL30 FEG, at $15 \mathrm{kV}$ using the backscattered electron signal.

EDX analyses in the SEM microscope were acquired without standards at $15 \mathrm{kV}$ with an EDAX liquid Nitrogen cooled $\mathrm{Si}(\mathrm{Li})$ detector.

\subsubsection{Surface analysis by X-ray photoelectron spectroscopy (XPS)}

XPS was performed with a Theta Probe system from Thermo Fisher Scientific. The system utilizes monochromatized $\mathrm{Al} \mathrm{K}_{\alpha} \mathrm{X}$-rays with an energy of $1486.7 \mathrm{eV}$ as the source and the spot size was set to $400 \mu \mathrm{m}$ (diameter). A hemispherical analyzer was used for data acquisition and the data were analyzed with the Avantage software package version 5.979 from Thermo Fisher.

\subsubsection{Bulk analysis by ICP-OES}

The catalyst samples were decomposed by fusion with potassium pyrosulphate, and dissolved by adding concentrated hydrochloric acid. The element concentration was determined using a Perkin 
Elmer model Optima 3000 ICP/OES analyser. The corresponding Mo/Fe ratio of the measured samples are shown in Table 1.

\subsubsection{BET-surface area}

The specific surface area (SSA) was measured on the fresh catalysts, after degassing at $350{ }^{\circ} \mathrm{C}$ under vacuum, by nitrogen adsorption at its boiling point using multipoint BET theory with four points in the $\mathrm{p} / \mathrm{p}_{0}=0.15$ to 0.3 range (Quantachrome NOVAtouch LX2). The corresponding surface areas of the measured samples are shown in Table 1.

\subsection{Catalyst Samples}

The catalyst samples in this study are named by their Mo/Fe ratio and the structure of the initially present $\mathrm{MoO}_{3}$ phase. For example, the sample with a Mo/Fe ratio of 2.0 and an initial hexagonal structure of the $\mathrm{MoO}_{3}$ phase $\left(\mathrm{h}-\mathrm{MoO}_{3}\right)$ is named FeMo_2.0h.

Table 1 - Atomic Mo/Fe bulk ratio according to ICP-OES and specific surface area according to BET.

\begin{tabular}{lcc}
\hline Sample & Mo/Fe Bulk Ratio & Specific Surface Area $\left[\mathbf{m}^{2} / \mathbf{g}\right]$ \\
\hline FeMo_1.6h & 1.63 & 6.8 \\
FeMo_2.0h & 1.98 & 7.8 \\
FeMo_2.0 $\alpha[24]$ & 2.01 & 4.7 \\
\hline
\end{tabular}




\section{Results and discussion}

\subsection{Catalytic activity measurements}

Figure 1 shows the methanol conversion as function of time on stream for the three FeMo catalysts investigated in this study and a commercial reference catalyst $(\mathrm{Mo} / \mathrm{Fe}=2.6)$. The combined selectivity towards formaldehyde and the reversible side product DME was above $97 \%$ and the bed temperature was $380-407{ }^{\circ} \mathrm{C}$ throughout all the experiments. The activation energy (Table 2) of the reaction on the catalysts was determined prior to each experiment by measuring the methanol conversion at increasing temperature and assuming a first order reaction in methanol, to calculate the rate constant as described in [24]. Based on the rate constants, the activation energy is obtained from corresponding the Arrhenius plot, see ESI Figure S6. The measured apparent activation energies in this study were similar to activation energies (61 and $57 \mathrm{~kJ} / \mathrm{mol}$ ) reported in the literature [32,33]. All activity measurements including selectivities to all measured products are shown in the ESI (Figures S1-4†).

Table 2 - Apparent activation energy for all catalyst samples.

\begin{tabular}{ll}
\hline Sample & $\begin{array}{l}\text { Activation } \\
\text { energy }[\mathrm{kJ} / \mathbf{m o l}]\end{array}$ \\
\hline FeMo_1.6h & 59 \\
FeMo_2.0h & 51 \\
FeMo_2.0 & 54 \\
Commercial & 63 \\
\hline
\end{tabular}


For all samples, the conversion decreased to approximately half of the initial conversion over a period of 10 to $40 \mathrm{~h}$, correlated with volatilization of all excess $\mathrm{MoO}_{3}$ [24, 25]. The sample with less $\mathrm{MoO}_{3}$ (FeMo_1.6h) and the sample with $\alpha-\mathrm{MoO}_{3}\left(\mathrm{FeMo} \_2.0 \alpha\right)$ lost activity faster than the sample with h$\mathrm{MoO}_{3}\left(\mathrm{FeMo} \_2.0 \mathrm{~h}\right)$ and the commercial sample with more $\alpha-\mathrm{MoO}_{3}(\mathrm{Mo} / \mathrm{Fe}=2.6)$. The initial decrease in conversion was followed by a slow increase throughout the $100 \mathrm{~h}$ on stream, as observed previously [24]. It should be noted that during the slow increase in activity, an increasing formation of $\mathrm{CO}$ was measurable (see ESI Figures S1 to S4†), which would lead to a decreased yield in an industrial plant operated at complete conversion of methanol. Furthermore, throughout the activity measurements the selectivity to DME was highest when the conversion was relatively low (see ESI Figures S1 to S4†). This is due to the reversible formation of DME from methanol. At higher conversion levels of methanol, DME is converted back to methanol, which decreases its overall selectivity. FeMo_1.6h, FeMo_2.0h and the commercial sample were heat treated after $100 \mathrm{~h}$ on stream, as described in the experimental section (Section 2.2). By heat treating the catalyst at $400{ }^{\circ} \mathrm{C}$ under an aerobic feed flow, the samples were partly reactivated, increasing the conversion by about 2-6 percentage points. Further reactivation by heat treatment at $500{ }^{\circ} \mathrm{C}$ significantly increased the conversion by about 17 percentage points relative to after the first $100 \mathrm{~h}$ on stream. 


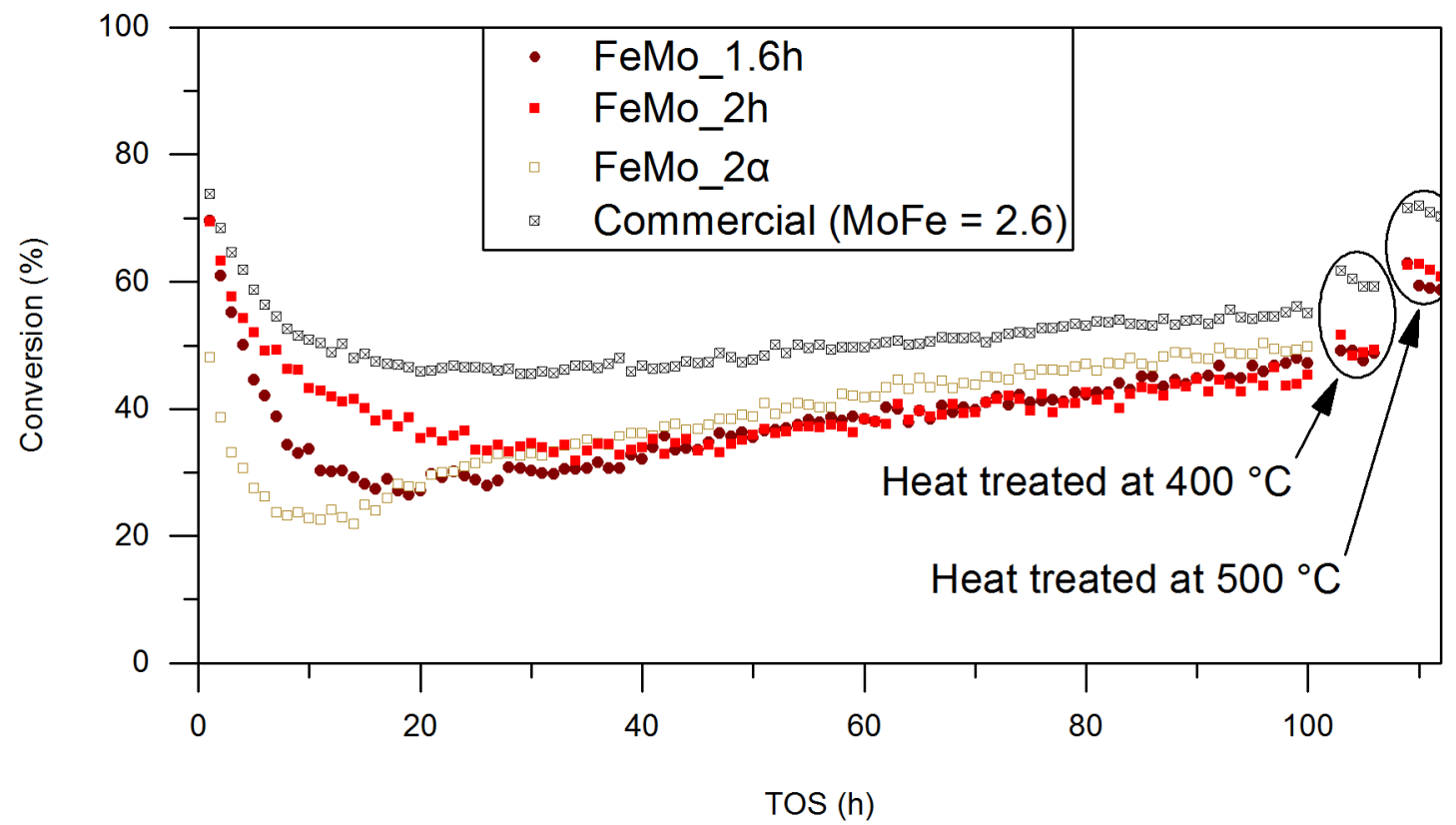

Figure 1 - MeOH conversion as function of time on stream for all samples. FeMo_2.0h, FeMo_1.6h and the commercial sample were reactivated at $400{ }^{\circ} \mathrm{C}$ after $100 \mathrm{~h}$, and again at $500{ }^{\circ} \mathrm{C}$ after $106 \mathrm{~h}$. Operating conditions: 25 mg catalyst mixed with $170 \mathrm{mg}$ $\mathrm{SiC}, \sim 157.5 \mathrm{NmL}$ min $^{-1}$ gas, feed composition: $10 \% \mathrm{O}_{2}, \sim 5 \% \mathrm{MeOH}$ in $\mathrm{N}_{2}$. During reactivation: $10 \% \mathrm{O}_{2}$ in $\mathrm{N}_{2}$. Oven temperature: $375{ }^{\circ} \mathrm{C}$ yielding a bed temperature of 380-407 ${ }^{\circ} \mathrm{C}$. Ambient pressure. FeMo_2.0 $\alpha$ is adapted from [24].

\subsection{Catalyst characterization}

The catalysts were characterized after synthesis and after the catalytic activity and deactivation measurements. An overview of the characterizations (XRD, Raman spectroscopy and XPS) is shown in Table 3.

In our previous work [24], a catalyst with $\mathrm{Mo} / \mathrm{Fe}=2.0$ was synthesized by the same hydrothermal method applied here, but followed by calcination at $535{ }^{\circ} \mathrm{C}$ in air, yielding a sample containing the thermodynamically stable $\alpha-\mathrm{MoO}_{3}$ phase, while the $\mathrm{MoO}_{3}$ phase present directly after synthesis was $\mathrm{h}-$ $\mathrm{MoO}_{3}$. In addition to the catalysts in this work, a commercial catalyst was provided by Haldor Topsøe A/S $(\mathrm{Mo} / \mathrm{Fe}=2.6)$ for reference. 
Table 3 - Overview of the fresh and spent catalyst characterization including XRD, Raman spectroscopy and XPS.

\begin{tabular}{|c|c|c|c|c|c|c|}
\hline \multirow[t]{2}{*}{ Sample } & \multirow[t]{2}{*}{$\begin{array}{l}\text { Phases by XRD } \\
\text { (Phase wt.\%) }\end{array}$} & \multirow{2}{*}{$\begin{array}{l}\text { Mo/Fe } \\
\text { bulk ratio } \\
\text { XRD }\end{array}$} & \multirow[t]{2}{*}{$\begin{array}{l}\text { Phases by Raman } \\
\text { Spectroscopy }\end{array}$} & \multirow{2}{*}{$\begin{array}{l}\mathrm{Mo} / \mathrm{Fe} \\
\text { surface } \\
\text { ratio XPS }\end{array}$} & \multicolumn{2}{|c|}{$\begin{array}{c}\text { XPS Binding } \\
\text { energy }(e V)\end{array}$} \\
\hline & & & & & $\begin{array}{l}\text { Mo } \\
\mathbf{3 d}_{5 / 2}\end{array}$ & $\begin{array}{c}\mathrm{Fe} \\
2 \mathbf{p}_{3 / 2}\end{array}$ \\
\hline $\begin{array}{l}\text { Fresh } \\
\text { FeMo_1.6h }\end{array}$ & $\begin{array}{l}\text { h- } \mathrm{MoO}_{3}(7) \\
\mathrm{Fe}_{2}\left(\mathrm{MoO}_{4}\right)_{3}(93)\end{array}$ & 1.6 & $\begin{array}{l}\text { h-MoO} \\
\mathrm{Fe}_{2}\left(\mathrm{MoO}_{4}\right)_{3}\end{array}$ & 1.74 & 233.2 & 712.1 \\
\hline $\begin{array}{l}\text { Spent } \\
\text { FeMo_1.6h }\end{array}$ & $\begin{array}{l}\mathrm{Fe}_{2}\left(\mathrm{MoO}_{4}\right)_{3}(85), \\
\mathrm{FeMoO}_{4}(15)\end{array}$ & 1.4 & $\mathrm{Fe}_{2}\left(\mathrm{MoO}_{4}\right)_{3}$ & 1.17 & 232.4 & 711.1 \\
\hline $\begin{array}{l}\text { Fresh } \\
\text { FeMo_2.0h }\end{array}$ & $\begin{array}{l}\mathrm{h}-\mathrm{MoO}_{3}(18), \\
\mathrm{Fe}_{2}\left(\mathrm{MoO}_{4}\right)_{3}(82)\end{array}$ & 2.0 & $\begin{array}{l}\mathrm{h}-\mathrm{MoO}_{3}, \\
\mathrm{Fe}_{2}\left(\mathrm{MoO}_{4}\right)_{3}\end{array}$ & 3.39 & 233.2 & 712.2 \\
\hline $\begin{array}{l}\text { Spent } \\
\text { FeMo_2.0h }\end{array}$ & $\begin{array}{l}\mathrm{Fe}_{2}\left(\mathrm{MoO}_{4}\right)_{3}(85) \\
\mathrm{FeMoO}_{4}(15)\end{array}$ & 1.4 & $\mathrm{Fe}_{2}\left(\mathrm{MoO}_{4}\right)_{3}$ & 1.69 & 232.5 & 711.5 \\
\hline $\begin{array}{l}\text { Fresh } \\
\text { FeMo_2.0 } \\
{[24]}\end{array}$ & $\begin{array}{l}\alpha-\mathrm{MoO}_{3}(17) \\
\mathrm{Fe}_{2}\left(\mathrm{MoO}_{4}\right)_{3}(83)\end{array}$ & 1.9 & $\begin{array}{l}\alpha-\mathrm{MoO}_{3}, \\
\mathrm{Fe}_{2}\left(\mathrm{MoO}_{4}\right)_{3}\end{array}$ & 6.09 & 232.0 & 710.8 \\
\hline $\begin{array}{l}\text { Spent } \\
\text { FeMo_2.0 } \\
{[24]}\end{array}$ & $\begin{array}{l}\mathrm{Fe}_{2}\left(\mathrm{MoO}_{4}\right)_{3}(69), \\
\mathrm{FeMoO}_{4}(31)\end{array}$ & 1.3 & $\begin{array}{l}\mathrm{Fe}_{2}\left(\mathrm{MoO}_{4}\right)_{3}, \\
\mathrm{FeMoO}_{4}\end{array}$ & 0.75 & 232.1 & 710.7 \\
\hline
\end{tabular}

\subsubsection{As prepared catalysts}

As described in section 2.1, the catalysts were synthesized with varying Mo/Fe ratios using a low temperature hydrothermal method. X-ray diffraction (XRD) patterns and Raman spectra (Figure 2) of the fresh catalyst samples confirmed the presence of $\mathrm{Fe}_{2}\left(\mathrm{MoO}_{4}\right)_{3}$ indicated by the reflection at $2 \theta=$ $25.7^{\circ}$ in the XRD patterns and bands at 782,966 and $990 \mathrm{~cm}^{-1}$ in the Raman spectra. Furthermore, the metastable $\mathrm{h}-\mathrm{MoO}_{3}$ phase was revealed by the reflection at $2 \theta=9.5^{\circ}$ and bands at 250,695 and 900 $\mathrm{cm}^{-1}$ in the XRD patterns and Raman spectra respectively [34]. The Mo/Fe ratio estimated from the phase composition measured by XRD of the fresh catalysts (Table 3) were similar to the ratio measured by ICP-OES (Table 1), which shows that the samples were crystalline. The presence of h- $\mathrm{MoO}_{3}$ in the 
fresh catalyst samples was due to the low temperature hydrothermal synthesis method. Similar preparation of $\mathrm{h}-\mathrm{MoO}_{3}$ by hydrothermal synthesis have been reported in the literature [35].

The scanning electron microscopy (SEM) images (Figure 3 (a) and (c)) coupled with energy dispersive X-ray spectroscopy (EDS) showed the morphology and elemental composition of the fresh catalyst samples. FeMo_1.6h (Figure 3 (a)) showed the presence of agglomerates of small $\mathrm{Fe}_{2}\left(\mathrm{MoO}_{4}\right)_{3}$ crystals. FeMo_2.0h (Figure 3 (c)) contained similar agglomerates of $\mathrm{Fe}_{2}\left(\mathrm{MoO}_{4}\right)_{3}$ crystals and hexagonal $\mathrm{MoO}_{3}$ crystals around 2-10 $\mu \mathrm{m}$ in size.

FeMo_2.0 $\alpha$, synthesized in our previous work [24], showed the presence of agglomerates of small $\mathrm{Fe}_{2}\left(\mathrm{MoO}_{4}\right)_{3}$ crystals and relatively small $\alpha-\mathrm{MoO}_{3}$ crystals around 1-2 $\mu \mathrm{m}$ in size (Figure 4 (a) and (b)), indicated by the reflection at $2 \theta=27.34^{\circ}$ in the XRD pattern and bands at $116,128,665,818$ and 993 $\mathrm{cm}^{-1}$ in the Raman spectrum. Clear differences in the $\mathrm{MoO}_{3}$ crystal sizes can be seen throughout samples FeMo_2.0h and FeMo_2.0 $\alpha$ in SEM images found in Figures S7 to S10 $\uparrow$ in the ESI. X-ray photoelectron spectroscopy (XPS) revealed the Mo/Fe ratio from the surface region of the fresh and spent samples (Table 3). With respect to the fresh samples, it must be taken into account that they consist of both $\mathrm{Fe}_{2}\left(\mathrm{MoO}_{4}\right)_{3}$ and $\mathrm{MoO}_{3}$, which yields a higher average $\mathrm{Mo} / \mathrm{Fe}$ ratio than the one expected for solely $\mathrm{Fe}_{2}\left(\mathrm{MoO}_{4}\right)_{3}$ crystals. The XPS spectra can be seen in ESI Figures $\mathrm{S} 11 \uparrow$ and $\mathrm{S} 12 \uparrow$. The spectra were fitted to one Mo $3 \mathrm{~d}_{3 / 2}-$ Mo $3 \mathrm{~d}_{5 / 2}$ doublet, which indicates the presence of several types of molybdenum (VI) oxide species. The Fe 2p $3 / 2$ peak was fitted to either one or two individual components, which might indicate the presence of two iron oxide species in oxidation state II and III respectively. However, these species closely overlap, which makes quantification of the separate species highly uncertain. The $\mathrm{Fe} 2 \mathrm{p}_{3 / 2}$ binding energies are reported as fitted to a single $\mathrm{Fe} 2 \mathrm{p}_{3 / 2}$ peak. 
The binding energies can be seen in Table 3. Similar binding energies have been reported in the literature $[36,37]$. 

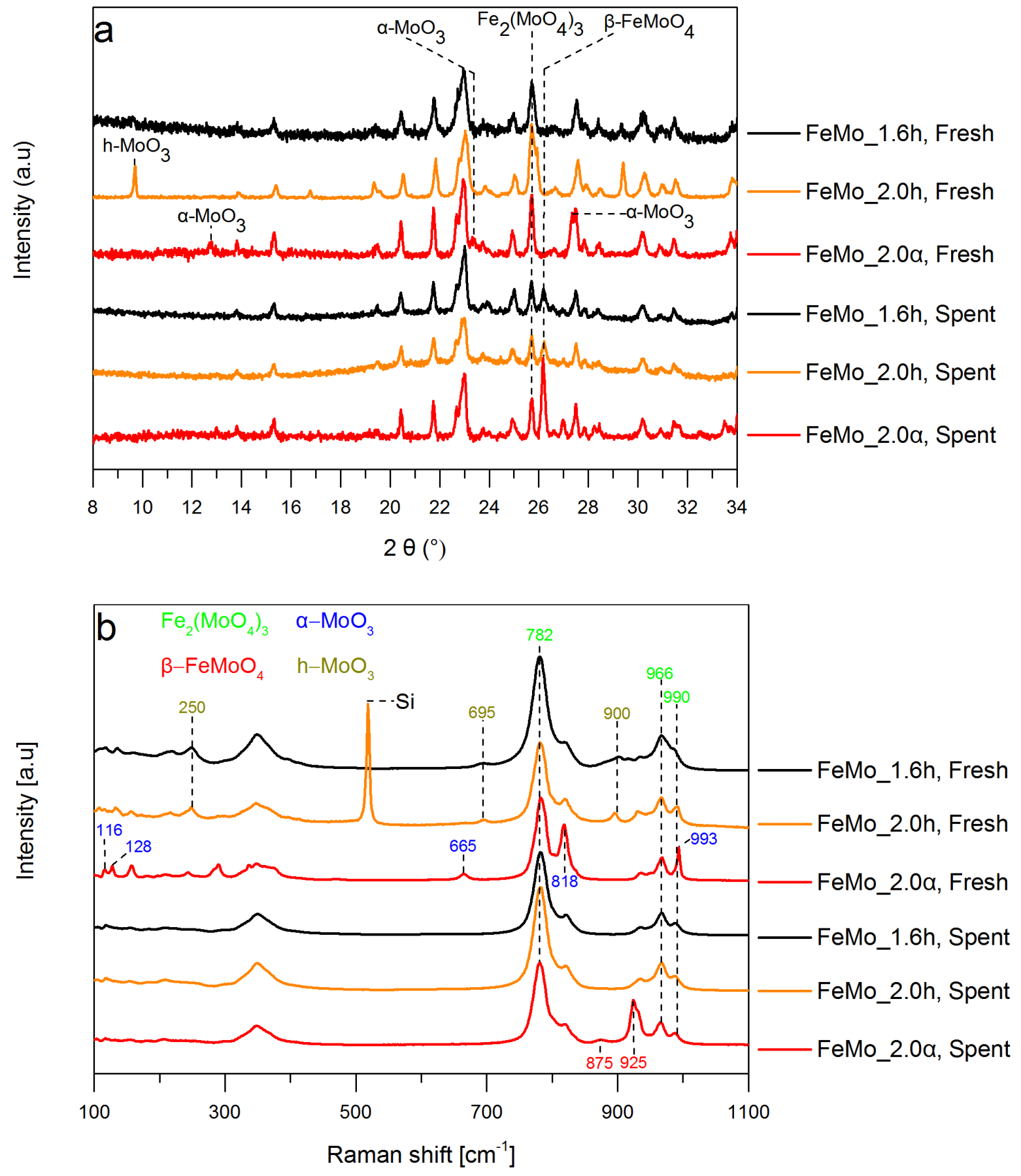

Figure 2 - (a) XRD patterns of the fresh and spent catalyst samples. (b) Raman spectra of the fresh and spent catalyst samples. A band at $518 \mathrm{~cm}^{-1}$ is observed for the fresh FeMo_2.0h, which is due to dilution of this sample with silicon. 


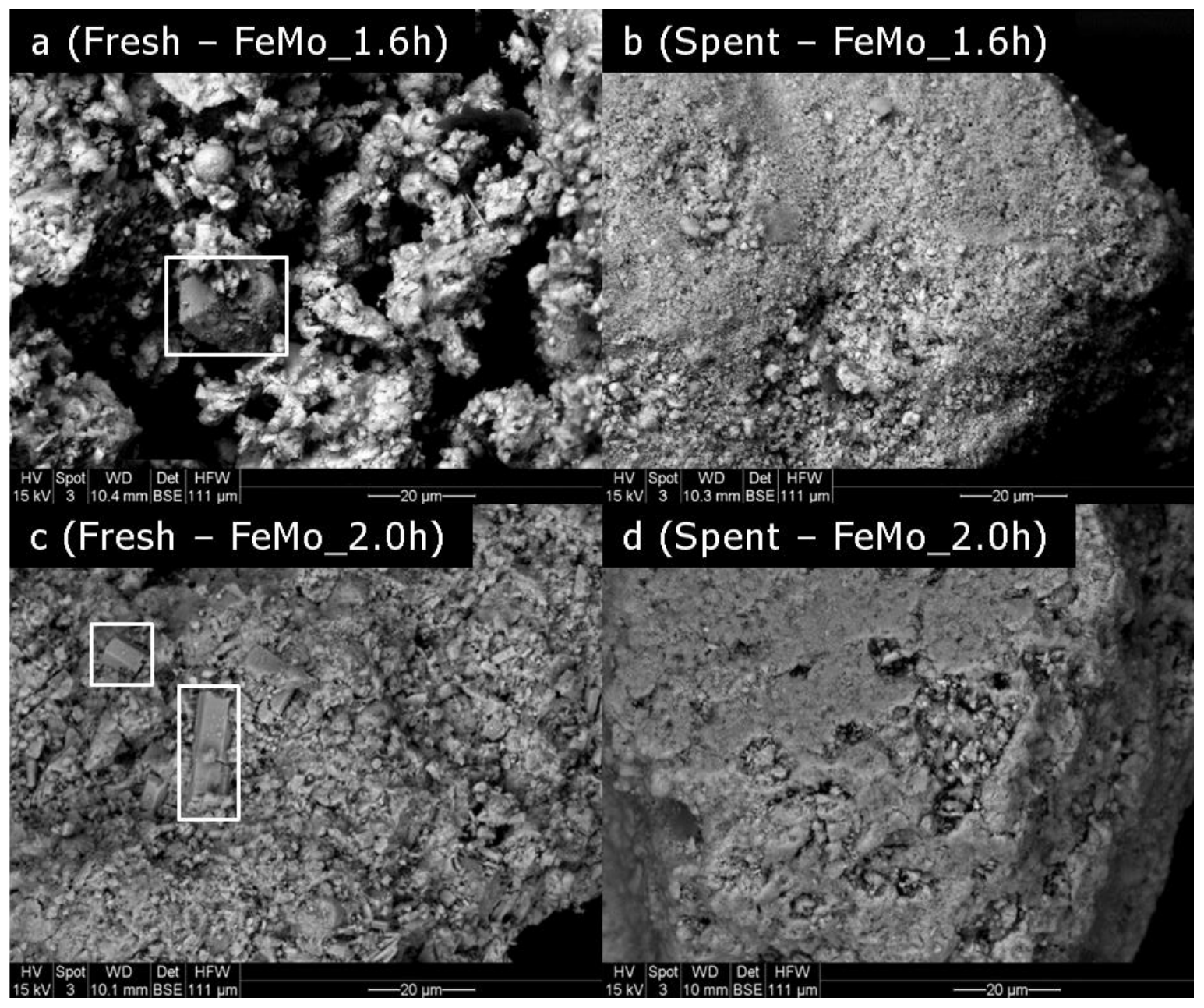

Figure 3 - SEM images of fresh and spent catalysts synthesized during this work. White rectangles mark h-MoO3 crystals.

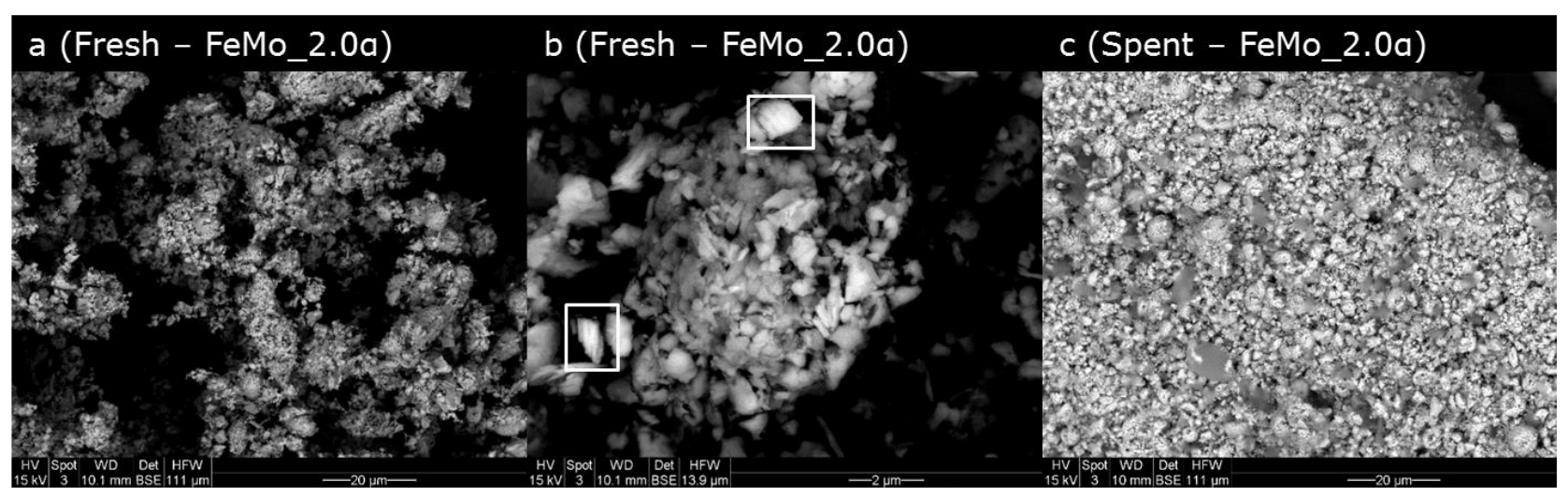

Figure 4 - SEM images of fresh and spent catalyst (FeMo_2.0 $\alpha$ ). White rectangles mark $\alpha$-MoO3 crystals. Data adapted from Raun et al. [24]. 


\subsubsection{Spent catalyst}

XRD patterns (Figure 2 (a)) confirmed that the spent catalysts were significantly depleted of $\mathrm{MoO}_{3}$, as the reflections at $2 \theta=9.5$ and $27.3^{\circ}$ belonging to $\mathrm{h}-\mathrm{MoO}_{3}$ and $\alpha-\mathrm{MoO}_{3}$ respectively were not observed. This depletion of Mo was expected from our previous work [24]. Likewise, SEM images (Figure 3 (b) and (d) and Figure 4 (c)) showed none of the initially present Mo rich crystals. $\mathrm{Fe}_{2}\left(\mathrm{MoO}_{4}\right)_{3}$ was still observed by both XRD reflection at $2 \theta=25.7^{\circ}$ and Raman spectroscopy bands as 782,966 and 990 $\mathrm{cm}^{-1}$ (Figure 2). Furthermore, $\mathrm{FeMoO}_{4}$ was detected by reflections in the XRD patterns at $2 \theta=26.2^{\circ}$. Detection of $\mathrm{FeMoO}_{4}$ by Raman spectroscopy is difficult due to a low Raman scattering cross section and was only clearly observed for the spent FeMo_2.0 $\alpha$ sample (bands at 875 and $925 \mathrm{~cm}^{-1}$ ). XPS revealed that the surface region of FeMo_2.0 $\alpha$ was significantly depleted for Mo. FeMo_2.0h, which had been reactivated by heat treatment, had an over-stoichiometric Mo content with $\mathrm{Mo} / \mathrm{Fe}=$ 1.69 at the surface. FeMo_1.6h, which was likewise reactivated, revealed a Mo/Fe ratio of 1.17. It must be taken into account that the XPS signal originates not only from the surface, but from the top 1-2 nm of the sample. The surface monolayer thus might have a higher $\mathrm{Mo} / \mathrm{Fe}$ ratio than the one measured. Nevertheless, the two catalysts heat treated after $100 \mathrm{~h}$ on stream showed higher Mo content in the surface region when compared to the spent FeMo_2.0 $\alpha$ catalyst.

\section{Discussion}

\subsubsection{Stability of catalyst}

For catalysts with an overstoichiometric Mo/Fe ratio, applying hydrothermal synthesis led to presence of the metastable h-MoO3 phase for the excess molybdenum oxide (Table 3). In the case of FeMo_2.0 $\alpha$ [24], the catalyst was calcined at $535^{\circ} \mathrm{C}$ for $2 \mathrm{~h}$ in air as the last step of the synthesis, yielding the 
thermodynamically stable $\alpha-\mathrm{MoO}_{3}$ phase. For the two samples with a Mo/Fe ratio of 2.0, SEM images (Figure 3 (c) and Figure 4 (b)) show the variation of their morphology. While both FeMo_2.0h and FeMo_2.0 $\alpha$ consisted of $\mathrm{Fe}_{2}\left(\mathrm{MoO}_{4}\right)_{3}$, relatively large h-MoO 3 crystals $(2-10 \mu \mathrm{m})$ were found for FeMo_2.0h and relatively small $\alpha-\mathrm{MoO}_{3}$ crystals $(\leq 2 \mu \mathrm{m})$ were found for FeMo_2.0 $\alpha$.

The initial methanol conversion of FeMo_2.0 $(48 \%)$ was significantly lower than that of FeMo_2.0h (69\%). The lower activity is likely due to sintering during calcination as indicated by the SSA of the fresh samples (4.7 and $7.8 \mathrm{~m}^{2} / \mathrm{g}$ respectively, Table 1). As discussed in the introduction (Section 1), the excess $\mathrm{MoO}_{3}$ is present in the catalyst to provide high activity and selectivity and to counter the loss of Mo from the active $\mathrm{Fe}_{2}\left(\mathrm{MoO}_{4}\right)_{3}$ phase. Although FeMo_2.0h and FeMo_2.0 $\alpha$ possess an equal amount of $\mathrm{MoO}_{3}$, the period for the decrease from initial to minimum activity varied significantly: $40 \mathrm{~h}$ for FeMo_2.0h compared to only $10 \mathrm{~h}$ for FeMo_2.0 $\alpha$. We have previously shown that the point of minimum activity corresponds to complete evaporation of all excess $\mathrm{MoO}_{3}$ with only $\mathrm{Fe}_{2}\left(\mathrm{MoO}_{4}\right)_{3}$ left in the catalyst [24][25]. The effect of a $\mathrm{MeOH}$ containing atmosphere on the $\mathrm{MoO}_{3}$ structure was studied by operando Raman spectroscopy (Figure S13†). Bands related to the thermodynamically less stable h- $\mathrm{MoO}_{3}$ at 693 and $900 \mathrm{~cm}^{-1}$ rapidly disappeared within 20 minutes on stream at $375^{\circ} \mathrm{C}$ and clear bands ascribed to $\alpha-\mathrm{MoO}_{3}\left(284,661\right.$ and $\left.991 \mathrm{~cm}^{-1}\right)$ evolved simultaneously. Hu et al. [23] have shown that after calcination of $\mathrm{h}-\mathrm{MoO}_{3}$ in air at a proper temperature around $420-440{ }^{\circ} \mathrm{C}, \alpha-\mathrm{MoO}_{3}$ is obtained by the process of in situ phase transformation and the morphology of the precursor (h- $\left.\mathrm{MoO}_{3}\right)$ is mainly maintained. Hence, the presence of $\mathrm{MeOH}$ vapors lowers the temperature for rearrangement of h-MoO 3 into $\alpha-\mathrm{MoO}_{3}$. The rapid rearrangement of the h- $\mathrm{MoO}_{3}$ structure into $\alpha-\mathrm{MoO}_{3}$ indicates that the higher stability of FeMo_2.0h compared to FeMo_2.0 $\alpha$ cannot be ascribed to the different crystals 
phases, but rather to the larger $\mathrm{MoO}_{3}$ crystals in FeMo_2.0h (Figure 3(c)). Large $\mathrm{MoO}_{3}$ crystals have a lower surface area which is likely to result in a lower rate of Mo volatilization.

Furthermore, the commercial catalyst had a Mo/Fe ratio of 2.6 and was prepared by co-precipitation followed by calcination, which yielded a catalyst containing $\alpha-\mathrm{MoO}_{3}$. The time for the initial decrease in activity of the commercial catalyst sample was roughly similar to the time for sample FeMo_2.0h, even though it contained a two-fold higher amount of excess $\mathrm{MoO}_{3}$. This was likely because the commercial catalyst also contained smaller $\alpha-\mathrm{MoO}_{3}$ crystals, similar to FeMo_2.0 $\alpha$, which volatilized faster than the larger h- $\mathrm{MoO}_{3}$ crystals in sample FeMo_2.0h. However, the higher amount of $\mathrm{MoO}_{3}$ makes the stability of the two catalysts roughly similar. Consistent with this, the times for deactivation from initial to minimum activity for samples FeMo_1.6h and FeMo_2.0 $\alpha$ were also similar, despite the lager amount of excess $\mathrm{MoO}_{3}$ in FeMo_2.0 $\alpha$.

As discussed in the introduction, it is of high importance to obtain an active, selective and stable catalyst with a minimum amount and rate of $\mathrm{MoO}_{3}$ volatilization to extend the operating time of the process. Preparing the iron molybdate/molybdenum oxide catalyst with large crystals and lower amounts of excess h- $\mathrm{MoO}_{3}$ appears to be achieving exactly that.

\subsubsection{Reactivation of spent catalyst}

$\mathrm{MoO}_{x}$ is thermodynamically stable at the surface of the iron molybdate system [18][38], and crystals with mainly $\mathrm{MoO}_{x}$ in the surface layer and a mixed Fe-Mo oxide phase in the sublayers have been confirmed to be highly active [14][39]. The observed reactivation of FeMo_1.6h and FeMo_2.0h by heat treatment at 400 and $500{ }^{\circ} \mathrm{C}$ (Figure 1) was most likely due to formation of $\mathrm{MoO}_{x}$ at the $\mathrm{Fe}_{2}\left(\mathrm{MoO}_{4}\right)_{3}$ crystal surface under simultaneous formation of $\mathrm{FeMoO}_{4}$. The formed $\mathrm{MoO}_{x}$ will cover the catalyst surface, yielding a high activity. This was indicated by comparing the reactivated sample 
FeMo_2.0h with the non-reactivated catalyst FeMo_2.0 $\alpha$. The surface region of FeMo_2.0 $\alpha$ was depleted for Mo with a Mo/Fe surface ratio of 0.75, whereas the surface Mo/Fe ratio of FeMo_2.0h was over-stoichiometric (1.69) after reactivation at $500{ }^{\circ} \mathrm{C}$ (Table 3).

\section{Conclusions}

In the present study iron molybdate/molybdenum oxide catalysts $(\mathrm{Mo} / \mathrm{Fe}=1.6$, and 2.0$)$ for selective oxidation of methanol to formaldehyde were synthesized using low temperature hydrothermal synthesis and compared to a similar catalyst $(\mathrm{Mo} / \mathrm{Fe}=2.0)$ and a commercial reference catalyst $(\mathrm{Mo} / \mathrm{Fe}=2.6)$ both calcined at high temperature. The stability of the catalysts during operation was investigated by activity measurements for $100 \mathrm{~h}\left(25 \mathrm{mg}\right.$ catalyst, feed flow $=\sim 157.5 \mathrm{NmL} / \mathrm{min}, \sim 5 \% \mathrm{MeOH}, 10 \% \mathrm{O}_{2}$ in $\mathrm{N}_{2}$, temp. $=380-407^{\circ} \mathrm{C}$ ), and the fresh and spent catalysts were comprehensively characterized. For the hydrothermally synthesized catalysts, the excess $\mathrm{MoO}_{3}$ was present as the metastable h- $\mathrm{MoO}_{3}$. By calcination the thermodynamically stable $\alpha-\mathrm{MoO}_{3}$ formed. The commercial catalyst likewise contained $\alpha-\mathrm{MoO}_{3}$. All catalysts initially deactivated to a minimum activity (maximum deactivation) due to the loss of all excess $\mathrm{MoO}_{3}$, after which they re-activated. For the catalyst with slight excess of $\mathrm{MoO}_{3}(\mathrm{Mo} / \mathrm{Fe}=1.6)$ the time for maximum deactivation was $19 \mathrm{~h}$ on stream. For the catalyst with $\mathrm{Mo} / \mathrm{Fe}=2.0$ and $\mathrm{h}-\mathrm{MoO}_{3}$ the time to reach maximum catalyst deactivation was $\sim 40$ hours. Comparing the two catalysts with $\mathrm{Mo} / \mathrm{Fe}=2.0$ showed that the sample with $\mathrm{h}-\mathrm{MoO}_{3}$ was more stable than the sample containing $\alpha-\mathrm{MoO}_{3}$ ( $\sim 40 \mathrm{~h}$ versus $\sim 10 \mathrm{~h}$ to reach lowest activity). This shows that the crystal structure, crystal size and/or morphology of the excess $\mathrm{MoO}_{3}$ strongly affect the catalyst stability. Operando Raman spectroscopy showed that the initially present h- $\mathrm{MoO}_{3}$ phase quickly rearranged to the $\alpha-\mathrm{MoO}_{3}$ phase. This indicates that the increased stability was mainly due to the presence of 
relatively large $\mathrm{h}-\mathrm{MoO}_{3}$ crystals $(2-10 \mu \mathrm{m})$ compared to relatively small $\alpha-\mathrm{MoO}_{3}$ crystals $(1-2 \mu \mathrm{m})$. The larger crystals of $\mathrm{h}-\mathrm{MoO}_{3}$ have a lower specific surface area from where volatilization of Mo can occur leading to increased stability of the catalyst.

This work shows for the first time the stabilizing effect of large hexagonal $\mathrm{MoO}_{3}$ crystals on the iron molybdate catalyst by measuring the catalytic activity for an extended period of time in which complete volatilization of the excess $\mathrm{MoO}_{3}$ phase occurs. Furthermore, the possibility for reactivation of spent catalysts by heat treatment was shown. During heat treatment Mo segregated to the surface of the iron molybdate crystals in the catalyst which improved the activity.

\section{Conflict of interest}

There are no conflicts to declare.

\section{Acknowledgments}

This work is a collaboration between the CHEC research center at The Department of Chemical and Biochemical Engineering at Technical University of Denmark (DTU) and Haldor Topsøe A/S. We thank the Independent Research Fund Denmark for the financial support (DFF - 4184-00336).

\section{Electronic Supplementary Information}

Activity, selectivity and carbon mole balance measurements, reference Raman spectra, Arrhenius plots, SEM images of sample FeMo_2.0h and FeMo_2.0 $\alpha$, XPS spectra and operando Raman spectra for the FeMo_2.0h sample. 


\section{References}

1. Merchant Research \& Consulting ltd (2016) World Formaldehyde Production to Exceed 52 Mln Tonnes in 2017

2. IHS Chemical (2013) IHS analysis report Forecast: global formaldehyde market demand after five years

3. Bahmanpour AM, Hoadley A, Tanksale A (2014) Critical review and exergy analysis of formaldehyde production processes. Rev Chem Eng 30:. https://doi.org/10.1515/revce-20140022

4. Magnusson A, Thevenin P (2018) In: Informally speaking (newsletter from Formox), winter $2017 / 2018$

5. Günther R, Disteldorf W, Gamer AO, Hilt A (2012) Ullmann's encyclopedia of industrial chemistry. Weinheim Chapter 4:Chapter 4

6. Ivanov KI, Dimitrov DY (2010) Deactivation of an industrial iron-molybdate catalyst for methanol oxidation. Catal Today 154:250-255.

https://doi.org/http://dx.doi.org/10.1016/j.cattod.2010.03.051

7. Soares APV, Portela MF, Kiennemann A (2005) Methanol Selective Oxidation to Formaldehyde over Iron-Molybdate Catalysts. Catal Rev 47:125-174. https://doi.org/10.1081/CR-200049088

8. Söderhjelm E, House MP, Cruise N, et al (2008) On the synergy effect in MoO3 -F 2(MoO4)3 catalysts for methanol oxidation to formaldehyde. Top Catal 50:145-155. https://doi.org/10.1007/s11244-008-9112-1

9. Bowker M, Carley AF, House M (2008) Contrasting the behaviour of MoO3 and MoO2 for the oxidation of methanol. Catal Letters 120:34-39. https://doi.org/10.1007/s10562-007-9255-X

10. Yeo BR, Pudge GJF, Bugler KG, et al (2016) The surface of iron molybdate catalysts used for the selective oxidation of methanol. Surf Sci 648:163-169.

https://doi.org/10.1016/j.susc.2015.11.010

11. Brookes C, Wells PP, Dimitratos N, et al (2014) The Nature of the Molybdenum Surface in Iron Molybdate. The Active Phase in Selective Methanol Oxidation. J Phys Chem C 118:2615526161. https://doi.org/10.1021/jp5081753

12. Bowker M, Brookes C, Carley AF, et al (2013) Evolution of active catalysts for the selective oxidative dehydrogenation of methanol on Fe2O3 surface doped with Mo oxide. Phys Chem Chem Phys 15:11988-12003. https://doi.org/10.1039/c3cp50399b

13. Bowker M, House M, Alshehri A, et al (2015) Selectivity determinants for dual function catalysts: applied to methanol selective oxidation on iron molybdate. Catal Struct React 1:95100. https://doi.org/10.1179/2055075815Y.0000000002

14. Rellán-Piñeiro M, López N (2015) The active molybdenum oxide phase in the methanol oxidation to formaldehyde (Formox process): A DFT study. ChemSusChem 8:2231-2239. https://doi.org/10.1002/cssc.201500315

15. Popov BI, Bibin VN, Boreskov GK (1976) Study of an iron-molybfate oxide catalyst for oxidation of methanol to formaldehyde. Kinet Catal 17:322-327

16. Andersson A, Hernelind M, Augustsson O (2006) A study of the ageing and deactivation phenomena occurring during operation of an iron molybdate catalyst in formaldehyde production. Catal Today 112:40-44. https://doi.org/10.1016/j.cattod.2005.11.052

17. Pernicone N (1991) Deactivation of Fe-Mo oxide catalyst in industrial plant and simulation tests 
on laboratory scale. Catal Today 11:85-91. https://doi.org/10.1016/0920-5861(91)87009-C

18. Xu Q, Jia G, Zhang J, et al (2008) Surface phase composition of iron molybdate catalysts studied by UV Raman spectroscopy. J Phys Chem C 112:9387-9393. https://doi.org/10.1021/jp800359p

19. Vieira Soares AP, Farinha Portela M, Kiennemann A (2005) Methanol selective oxidation to formaldehyde over iron-molybdate catalysts. Catal. Rev. - Sci. Eng. 47:125-174

20. Lohbeck K, Haferkorn H, Fuhrmann W, Fedtke N (2005) Manganese and Manganese Alloys. Ullmann's Encycl Ind Chem 413-454. https://doi.org/10.1002/14356007.a16

21. McCarron EMI (1986) $\beta$-Mo03: a Metastable Analogue of WO3. J Chem Soc, Chem Commun 101:336-338

22. Dhage SR, Hassan MS, Yang OB (2009) Low temperature fabrication of hexagon shaped hMoO3 nanorods and its phase transformation. Mater Chem Phys 114:511-514. https://doi.org/10.1016/j.matchemphys.2008.10.076

23. Hu H, Deng C, Xu J, et al (2015) Metastable h -MoO 3 and stable $\alpha$-MoO 3 microstructures: controllable synthesis, growth mechanism and their enhanced photocatalytic activity. J Exp Nanosci 10:1336-1346. https://doi.org/10.1080/17458080.2015.1012654

24. Raun KV, Lundegaard LF, Chevallier J, et al (2018) Deactivation behavior of an iron-molybdate catalyst during selective oxidation of methanol to formaldehyde. Catal Sci Technol 8:46264637. https://doi.org/10.1039/C8CY01109E

25. Gaur A, Schumann M, Raun KV, et al (2019) Operando XAS/XRD and Raman Spectroscopic Study of Structural Changes of the Iron Molybdate Catalyst during Selective Oxidation of Methanol. ChemCatChem Accepted: https://doi.org/10.1002/cctc.201901025

26. Beale AM, Jacques SDM, Sacaliuc-Parvalescu E, et al (2009) An iron molybdate catalyst for methanol to formaldehyde conversion prepared by a hydrothermal method and its characterization. Appl Catal A Gen 363:143-152. https://doi.org/10.1016/j.apcata.2009.05.008

27. Høj M, Kessler T, Beato P, et al (2014) Structure, activity and kinetics of supported molybdenum oxide and mixed molybdenum-vanadium oxide catalysts prepared by flame spray pyrolysis for propane OHD. Appl Catal A Gen 472:29-38.

https://doi.org/10.1016/j.apcata.2013.11.027

28. Leeuwen ME Van (1994) Derivation of Stockmayer potential parameters. Fluid Phase Equilib 99:1-18

29. Tee LS, Gotoh S, Stewart WE (1966) Molecular Parameters for Normal Fluids. Lennard-Jones 12-6 Potential. Ind Eng Chem Fundam 5:356-363. https://doi.org/10.1021/i160019a011

30. Mourits FM, Rummens FHA (1977) A critical evaluation of Lennard-Jones and Stockmayer potential parameters and of some correlation methods. Can J Chem 55:3007-3020. https://doi.org/10.1139/v77-418

31. Coelho AA (2018) TOPAS and TOPAS-Academic: an optimization program integrating computer algebra and crystallographic objects written in C++. J Appl Cryst 51:210-218

32. Braz CG, Mendes A, Rocha J, et al (2019) Model of an industrial multitubular reactor for methanol to formaldehyde oxidation in the presence of catalyst deactivation. Chem Eng Sci 195:347-355. https://doi.org/10.1016/J.CES.2018.09.033

33. Drăgan S, Kulic I (2016) A macrokinetic study of the oxidation of methanol to formaldehyde on Fe2O3 - MoO3 oxide catalyst. Stud Univ Babes-Bolyai, Chem 61:

34. Lunk HJ, Hartl H, Hartl MA, et al (2010) "Hexagonal molybdenum trioxide" - Known for 100 years and still a fount of new discoveries. Inorg Chem 49:9400-9408. 
https://doi.org/10.1021/ic101103g

35. Schuh K, Kleist W, Høj M, et al (2014) Selective oxidation of propylene to acrolein by hydrothermally synthesized bismuth molybdates. Appl Catal A Gen 482:145-156. https://doi.org/10.1016/j.apcata.2014.05.038

36. Bowker M, Holroyd R, House M, et al (2008) The Selective Oxidation of Methanol on Iron Molybdate Catalysts. Top Catal 48:158-165. https://doi.org/10.1007/s11244-008-9058-3

37. Peláez R, Marín P, Ordóñez S (2016) Synthesis of formaldehyde from dimethyl ether on alumina-supported molybdenum oxide catalyst. Appl Catal A Gen 527:137-145. https://doi.org/10.1016/j.apcata.2016.09.002

38. Brookes C, Wells PP, Cibin G, et al (2014) Molybdenum Oxide on Fe2O3 Core-Shell Catalysts: Probing the Nature of the Structural Motifs Responsible for Methanol Oxidation Catalysis. ACS Catal 4:243-250. https://doi.org/10.1021/cs400683e

39. Fagherazzi G, Pernicone N (1970) Structural study of a methanol oxidation catalyst. J Catal 16:321-325. https://doi.org/10.1016/0021-9517(70)90228-9 